\title{
RESENHA: GAME LOCALIZATION: TRANSLATING FOR THE GLOBAL ENTERTAINMENT INDUSTRY
}

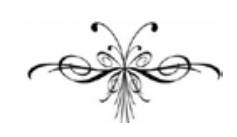 \\ FERNANDO DA SILVA ${ }^{1}$
}

O'HAGAN, Minako; MANGIRON, Carmen. Game Localization: Translating for the global entertainment industry. Amsterdam/Philadelphia: John Benjamins, 2013. 374 p.

$\mathrm{N}$ o livro Game Localization: Translating for the global entertainment industry, Minako O’Hagan e Carmen Mangironi estabelecem importantes pressupostos teóricos e práticos acerca da localização de jogos digitais, sua relevância no mercado global de entretenimento, e o redimensionamento dessa prática dentro da área dos Estudos da Tradução. De início, em seu prefácio as autoras expõem a necessidade de definir um enquadramento mais claro para o que até então se percebe ser um posicionamento periférico da localização de jogos na academia e, em certo grau, na indústria de desenvolvimento de software.

Dividido em sete capítulos, o livro promove de maneira coordenada e meticulosa uma contextualização acerca dos principais aspectos constitutivos da pesquisa, da prática, e do treinamento para a localização de jogos digitais. $\mathrm{Na}$ intenção de estabelecer um paralelo claro entre os Estudos da Tradução e o campo da prática de localização de jogos digitais, o livro apresenta os espaços interdisciplinares a serem preenchidos para um melhor diálogo entre aspectos de natureza operacional que envolvem o desenvolvimento de jogos e a relevância da tradução neste processo. O escopo das discussões apresentadas no livro também abarca questionamentos acerca da adequação do presente aparato teórico dos Estudos da Tradução para a realização de pesquisas relacionadas à tradução de recursos semióticos audiovisuais e culturalmente marcados, como é o caso da localização de jogos digitais.

\footnotetext{
${ }^{1}$ Fernando da Silva é bacharel em Letras de língua inglesa e literatura pela Universidade Federal de Santa Catarina (UFSC), mestre em Estudos de Tradução (PGET - UFSC) e doutorando pelo mesmo programa de pós-graduação. Atualmente faz sua pesquisa de doutorado com foco em jogos digitais localizados e análise de corpora multimodais dentro do par linguístico inglês-português.
} 
Um aspecto importante que O’Hagan e Mangiron abarcam, e que se torna inerente a uma teorização sobre a tradução e parte de seus paradigmas de interculturalidade, é enxergar a localização de jogos a partir de seu local de distribuição e de uma perspectiva claramente funcionalista, isto é, a localização de jogos ganha contornos culturais, étnicos, religiosos, geopolíticos, além de estritamente linguísticos, a partir das relações estabelecidas entre o país em que o jogo é desenvolvido e onde o jogo será comercializado. A perspectiva de um olhar sistemático e global acerca da localização de jogos digitais é apresentada no livro como forma de operacionalizar e otimizar não só a pesquisa na área, mas também atender as demandas e preocupações de desenvolvedores e distribuidores da indústria de jogos.

No primeiro capítulo, o livro apresenta uma visão ampla acerca do desenvolvimento da localização de jogos digitais, atribuindo à essa modalidade de tradução não apenas um valor histórico dentro de seu campo industrial e em um mercado global em expansão, mas também como um instrumento de reflexão acerca dos próprios paradigmas práticos e teóricos dentro dos Estudos da Tradução. O’Hagan e Mangiron apresentam informações introdutórias acerca do conceito de videogame, bem como diferentes gêneros de plataforma, a relação dos jogos com outras mídias de entretenimento - como filmes, desenhos animados, histórias em quadrinhos, livros, a partir do fenômeno da transmidialidade -, além das limitações práticas e teóricas impostas à localização de jogos. Por fim, oferecem um panorama introdutório dos outros capítulos acerca da estrutura da indústria de desenvolvimento de jogos, atribuindo à localização um grau de importância fundamental nos primeiros estágios de desenvolvimento de um produto.

No segundo capítulo do livro, é oferecido ao leitor uma aprofundada reflexão acerca dos principais paradigmas da localização, sua relação com a área dos Estudos da tradução e localização de software em um sentido mais amplo. A partir de outros referenciais teóricos, as autoras discutem aspectos da representação do conceito de localização e suas potenciais implicações na constituição de um campo disciplinar independente. O’Hagan e Mangiron apontam que uma das principais razões pela qual ainda parece existir uma tensão entre os conceitos de localização e tradução advém de uma falta de reconhecimento da localização por parte dos Estudos da Tradução como um fenômeno de relevância epistêmica.

O terceiro capítulo oferece ao leitor um panorama geral acerca dos principais modelos de localização, os principais estágio de localização dentro de um projeto de desenvolvimento de um jogo, as principais ferramentas utilizadas, e a inserção dessa prática dentro de um arcabouço de globalização, internacionalização, localização e tradução (GILT). O’Hagan e Mangiron também oferecem um apanhado geral das informações que um desenvolvedor deve repassar à uma equipe de localização para assegurar a qualidade de um grande projeto. As autoras observam que para assegurar a qualidade de um jogo localizado, os desenvolvedores devem tornar disponíveis à equipe de localização dados gerais sobre o projeto e seu conteúdo; materiais de referência; programas e ferramentas de auxílio à tradução; códigos de programação do jogo, e os conteúdos a serem localizados, além de noções acerca das especificidades culturais e de mercado do lugar onde o jogo será distribuído.

No quarto capítulo, o livro estabelece uma relação mais clara entre a localização de jogos e os Estudos da Tradução, a partir de um olhar que se aproxima de modelos teóricos específicos da tradução, como o funcionalismo de 
Christiane Nord e a teoria do escopo de Hans Vermeer. A partir dessa ponte epistemológica, o capítulo apresenta ao leitor um conjunto de normas de localização a serem seguidas conforme as especificidades de cada jogo, assim como do mercado no quais serão distribuídos. Para melhor ilustrar as implicações inerentes ao uso de um conjunto de normas de localização de jogos, as autoras listam vários relatos de localizações prévias, apontando, de forma pragmática, estratégias de adaptação cultural e tradutória.

No quinto capítulo os conceitos de jogo e localização são abordados a partir da perspectiva da contextualização cultural. Jogos digitais e suas localizações são caracterizados como artefatos culturalmente marcados a partir de suas especificidades de conteúdo, moldados por diversas demandas de distribuição, a partir de uma cultura de partida, isto é, de um país onde um jogo é desenvolvido, e com vistas aos diferentes mercados para os quais tal jogo será localizado. Este capítulo apresenta ao leitor as principais variáveis envolvidas na localização de conteúdos em jogos digitais, que podem variar de órgãos regulatórios de censura à perspectiva de vendas num dado mercado de chegada.

No sexto capítulo, O’Hagan e Mangiron abordam as principais implicações pedagógicas relacionadas às demandas de treinamento de profissionais de localização de jogos. Salientam também como essa atividade emerge como um promissor campo de tralhado para profissionais de tradução. Ao fim do capítulo as autoras sugerem um esboço preliminar de uma grade curricular para a formação de localizadores, apresentado as bases teóricas multidisciplinares e práticas para a formação desses profissionais.

No sétimo capítulo, o livro aborda com maior amplitude alguns desdobramentos de pesquisa em localização de jogos e a relação com a área dos Estudos da Tradução. Particular atenção é dada a pesquisas relacionadas a jogos digitais e acessibilidade, e a suas inerentes implicações à prática e ao campo teórico da localização de jogos e da tradução. O’Hagan e Mangiron também discutem localizações feitas de forma não profissional, de fãs e entusiastas de videogames. Esse desdobramento da prática de localização expõe diversas facetas de representação dessa modalidade tradutória e da própria cultura que circunscreve a comunidade gamer. Para as autoras, a compreensão do conceito de acessibilidade aplicado a mídias de entretenimento, como é o caso de jogos digitais, deve observar a perspectiva de múltiplos grupos de usuários. A compreensão do conceito de acessibilidade aplicado aos jogos digitais deve estar circunscrita não apenas ao nível da adaptação de software, mas também ao desenvolvimento de hardwares que atendam às múltiplas demandas de jogadores portadores de necessidades especiais. Para promover a atenção a respeito do uso de tecnologias assistivas para jogos e consoles, é necessário que desenvolvedores, jogadores e outros grupos, como mídias de divulgação e distribuidores, fomentem o desenvolvimento e a inserção de tecnologias de acessibilidade a partir dos primeiros estágios de criação de um jogo..

No capítulo de conclusão as autoras oferecem um breve panorama sobre os principais pontos abordados ao longo do livro, explorando com uma ênfase maior a relação estabelecida entre localização e Estudos da Tradução.

Game Localization: Translating for the global entertainment industry apresenta a localização de jogos como uma atividade interdisciplinar, e estabelece espaços de coesão entre a tradução e outras áreas de conhecimento convergentes. A ampliação do conceito de localização a partir de uma dimensão cultural também se mostra relevante dentro da proposta do livro, pois reflete sobre o papel de um 
profissional de localização como mediador entre diferentes mercados consumidores. Vários exemplos de localizações são apresentados ao leitor ao longo do livro, traçando não apenas um panorama descritivo de práticas mal sucedidas ou bem implementadas de localização, mas também demarcando um conjunto de orientações de cunho prescritivo acerca dessa prática tradutória.

O’Hagan e Mangiron aproximam-se do arcabouço dos Estudos da Tradução a partir de teóricos como Pym, Chesterman, Bassnett, Lefevere, Munday, entre outros de similar relevância, estabelecendo relações de contraste e indicando um tensionamento epistemológico entre as atividades de localização e tradução . Um ponto importante levantado por O’Hagan e Mangiron é o fato de que, até o momento, uma possível justificativa para o tensionamento entre os conceitos de tradução e de localização pode ter tido como origem uma visão reducionista da tradução que se tornou prevalente na indústria. Algumas das críticas levantadas no livro a respeito da natureza teórica e prática da localização, ganham, de forma enfática, novos contornos, sobretudo a partir de vários relatos acerca de jogos localizados e os problemas oriundos de práticas de localização mal implementadas.

Outro aspecto relevante abordado pelo livro constitui-se no distanciamento da área de localização de jogos de práticas relacionadas, como a localização de softwares e a tradução audiovisual (TAV), a partir do que as autoras identificam agendas de pesquisas distintas. Em outras palavras, apesar de essas atividades compartilharem muitos aspectos práticos - como legendagem e dublagem, no caso da TAV, além das próprias demandas da localização de software -, a localização de jogos distancia-se de muitos dos paradigmas de pesquisa orientados ao produto e ao processo, comuns a ela à TAV. Esse distanciamento se dá uma vez que a localização de jogos estabelece um contato mais aproximado com o usuário final, a partir de novos ambientes de comunicação e colaboração, e à avaliação e crítica, a partir de comunidades virtuais, fóruns de discussão e produção de conteúdos, além da própria natureza de sua prática que se constitui em garantir ao jogador uma experiência de jogo satisfatória em termos linguísticos e culturais.

As diferentes relações que emergem entre mercados consumidores são fundamentais para um melhor entendimento dos fatores limitantes e contribuintes à localização de um jogo. No Brasil torna-se cada vez mais comum o lançamento de títulos localizados em simultaneidade com outros países, evidenciando não apenas a rentabilidade de nosso mercado, mas também uma maior penetração de grandes desenvolvedores em território nacional a partir de seus escritórios de representação. Essa presença direta em um mercado de consumo favorece ações diretas de marketing, além de aumentar a compreensão de um desenvolvedor acerca das especificidades culturais de um país e as preferências de um nicho de jogadores.

Para O’Hagan e Mangiron, estabelecer um traçado de historicidade relacionando a tradução e a localização à indústria de jogos significa evidenciar uma descontinuidade de paradigmas teóricos e práticos. Ainda assim, a proximidade entre as duas atividades contribuem para uma percepção redimensionada da localização de jogos e da tradução, dos pontos de vista de características textuais, estratégias, normas tradutórias, bem como estabelece uma linha divisória e delimitante acerca de seus aparatos de pesquisa. Pensar a localização de jogos a partir de uma perspectiva de manipulação linguística em diferentes níveis verbais favorece a compreensão de um conjunto de forças transformativas que auxiliam na recriação de todo o imaginário visual de um jogo, 
recriando suas regras, influenciando na criação de nomes de personagens e itens, narrativas, entre outros aspectos fundamentais da tarefa do localizador.

Por fim, Game Localization: Translating for the global entertainment industry torna-se uma referência fundamental para o encaminhamento de pesquisas na área de localização de jogos, tendo como ponto de partida a área dos Estudos da Tradução e dos Estudos sobre Jogos. Muitos dos posicionamentos teóricos apresentados no livro contribuem para uma discussão mais aprofundada que beneficia um diálogo maior entre a indústria e a academia.

Fernando da Silva

fe900571@gmail.com

Doutorando, Universidade Federal de Santa Catarina 